J. Dairy Sci. 92:3930-3938

doi:10.3168/jds.2008-1975

(c) American Dairy Science Association, 2009.

\title{
Effects of dilution rate and retention time of concentrate on efficiency of microbial growth, methane production, and ruminal fermentation in Rusitec fermenters
}

\author{
M. E. Martínez, M. J. Ranilla, S. Ramos, M. L. Tejido, and M. D. Carro ${ }^{1}$ \\ Departamento de Producción Animal, Universidad de León, 24007 León, Spain
}

\begin{abstract}
The objective of this study was to investigate the effects of 2 dilution rates (DL) and 2 concentrate retention times (RT) on microbial growth, methane production, and fermentation of a 30:70 alfalfa hay:concentrate diet in Rusitec fermenters maintained at similar $\mathrm{pH}$. The DL were 3.78 (low DL, LDL) and $5.42 \% /$ h (high DL, HDL), and concentrate RT was either $24 \mathrm{~h}$ (T24) or 48 $\mathrm{h}$ (T48). Forage RT was $48 \mathrm{~h}$ in all fermenters. Apparent disappearance of diet DM and NDF was greater in HDL fermenters compared with LDL fermenters, but there was a significant $\mathrm{DL} \times$ concentrate $\mathrm{RT}$ interaction, showing that the effect of DL was more pronounced in T48 compared with T24 fermenters. Methane production was not affected by DL, but was greater in T48 compared with T24 fermenters, which was consistent with the increased fiber degradation in T48 fermenters. Increasing DL augmented volatile fatty acid production and molar proportions of propionate, isovalerate, and valerate, and reduced those of caproate, but no effects were observed on acetate, butyrate, and isobutyrate proportions. Increasing concentrate RT resulted in greater volatile fatty acid production and proportions of acetate, butyrate, and caproate, but reduced those of propionate, valerate, and isovalerate. Ammonia-N production was not affected by concentrate RT, but was greater at HDL compared with LDL. Microbial growth was not affected by DL, but microbial growth efficiency was lower in HDL compared with LDL fermenters. Concentrate RT affected microbial growth and its efficiency, with both being greater in T48 compared with T24 fermenters. Carboxymetylcellulase and xylanase activities in ruminal fluid were greater in HDL compared with LDL fermenters, but were not affected by concentrate RT. There were DL $\times$ concentrate RT interactions for diet apparent disappearance, molar proportions of propionate, butyrate, isovalerate, and caproate, and acetate:propionate ratio, indicating
\end{abstract}

Received December 15, 2008.

Accepted March 10, 2009.

${ }^{1}$ Corresponding author: mdcart@unileon.es that effects of DL on these variables were influenced by concentrate RT. The results would indicate that using higher DL and shorter concentrate RT than those typically used in Rusitec fermenters would contribute to improving the simulation of in vivo fermentation of high-concentrate diets.

Key words: dilution rate, retention time, Rusitec, microbial growth

\section{INTRODUCTION}

Ruminal dilution rate (DL) and solids retention time (RT) have been identified as factors influencing ruminal fermentation and microbial growth, but results reported in the literature are controversial. Whereas some studies have indicated greater VFA production and microbial growth with increasing DL (Stern and Hoover, 1979; Meng et al., 1999) and decreasing solids RT (Hoover et al., 1982; Shriver et al., 1986; Schadt et al., 1999), no effects on VFA production (Isaacson et al., 1975; Hoover et al., 1984; Eun et al., 2004) or microbial growth (Hoover et al., 1984) have been found in others. Both DL and solids RT can be highly variable in vivo and are affected by several factors, including environment, physiological condition of the animal, dietary characteristics, and intake levels, among others (Stern et al., 2006). Therefore, it is necessary to determine what effects changes in DL and RT, per se, have on ruminal fermentation and efficiency of microbial growth (EMG) so that these conditions can be manipulated to support optimal microbial protein synthesis. Because of the difficulties in evaluating the influence of these factors in vivo, most of the available results are from in vitro studies conducted with ruminal fermenters. Experimental increases in DL are usually obtained by increasing the amount of artificial saliva entering the fermenters. This generally results in an increased buffering capacity of the system and, consequently, greater $\mathrm{pH}$. Therefore, effects of $\mathrm{DL}$ and $\mathrm{pH}$ on fermentation and microbial growth are often confounded, although Hoover et al. (1984) pointed out that at a constant solids RT, pH was more important than DL in controlling ruminal digestion. In addition, in the single-effluent, 
Table 1. Ingredients and chemical composition of the experimental diet

\begin{tabular}{lc}
\hline Item & Amount \\
\hline Ingredient, \% of DM & \\
Grass hay & 30 \\
Barley & 15.2 \\
Gluten feed & 14.5 \\
Wheat middlings & 13.8 \\
Soybean meal & 9.7 \\
Palm kernel meal & 9.0 \\
Wheat & 3.5 \\
Corn & 3.5 \\
Vitamin-mineral premix ${ }^{1}$ & 1.0 \\
Chemical composition of the diet & \\
DM, \% & 92.5 \\
OM, \% of DM & 90.9 \\
N, \% of DM & 2.70 \\
NDF, \% of DM & 35.9 \\
ADF, \% of DM & 17.4 \\
${ }^{15} \mathrm{~N}, \%$ N & 0.3674 \\
ME, Mcal/kg of DM & 2.45 \\
\hline
\end{tabular}

${ }^{1}$ Vitamin-mineral premix contained per kilogram of DM: 11,250 IU of vitamin $\mathrm{A} ; 2,250 \mathrm{IU}$ of vitamin $\mathrm{D}_{3} ; 25 \mathrm{mg}$ of vitamin $\mathrm{E}$; and $10 \mathrm{mg}$ of $\mathrm{CuSO}_{4} 5 \mathrm{H}_{2} \mathrm{O}$.

${ }^{2}$ Estimated according to the NRC (1985).

continuous-culture fermenters used in some experiments (Meng et al., 1999), solid and liquid fractions flow out of fermenters simultaneously, and increasing DL result in concomitant decreases in solids RT, thus making it difficult to separate the relative effect of each factor. In contrast, dual-effluent, continuous-culture fermenters allow a precise control of both DL and solids RT (Hoover et al., 1984; Schadt et al., 1999). In Rusitec fermenters, feed is incubated in nylon bags that are taken out daily at a fixed time, thus allowing for precise control of solids RT.

Finally, all information of which we are aware has been obtained in cattle, and to our knowledge, no studies investigating the effects of DL and solids RT in fermenters inoculated with ruminal fluid of sheep have been conducted to date. Because both DL and solids RT have been reported to be different in each species (Colucci et al., 1990), the aim of this work was to analyze the effect of DL and concentrate RT on ruminal fermentation and microbial growth in Rusitec fermenters inoculated with sheep ruminal fluid and maintained under similar $\mathrm{pH}$ conditions.

\section{MATERIALS AND METHODS}

\section{Apparatus, Animals, and Diet}

One 16-d incubation trial was carried out using 16 Rusitec fermenters (Czerkawski and Breckenridge, 1977). Fermenters had an effective volume of $600 \mathrm{~mL}$, and the general incubation procedure was as described by Giraldo et al. (2007). All fermenters received $30 \mathrm{~g}$ of DM of a 30:70 alfalfa hay:concentrate (DM basis) diet daily (Table 1). Hay was chopped (at approximately $0.5-\mathrm{cm}$ pieces), and the concentrate was ground through a $3-\mathrm{mm}$ sieve. Forage and concentrate were fed into separate nylon bags $(100-\mu \mathrm{m}$ pore; $8 \times 15 \mathrm{~cm}), 1$ containing $9 \mathrm{~g}$ of alfalfa hay and the other 21 of concentrate (DM basis).

The inoculum was obtained from 4 ruminally fistulated sheep fed the same diet administered to the fermenters for $21 \mathrm{~d}$ before beginning the in vitro trial. Sheep were managed according to the protocols approved by the León University Institutional Animal Care and Use Committee. On the first day of the experiment, each fermenter was inoculated with $250 \mathrm{~mL}$ of strained rumen fluid, $200 \mathrm{~mL}$ of artificial saliva, and $80 \mathrm{~g}$ of solid rumen content supplied in a nylon bag. Ruminal contents from each sheep were collected immediately before the morning feeding, mixed, strained through 2 layers of cheesecloth, and transferred to the fermenters within 30 min after collection. Mean value of $\mathrm{pH}$ in ruminal fluid was $6.47 \pm 0.173$.

\section{Experimental Procedure and Sampling}

The experiment had a factorial design with $2 \mathrm{DL}$, low (LDL) and high (HDL), and 2 concentrate RT times of $24 \mathrm{~h}$ (T24) and $48 \mathrm{~h}$ (T48). Forage RT was $48 \mathrm{~h}$ in all fermenters. Treatments were assigned randomly so that 4 fermenters received each of the treatments. Flow through the fermenters was maintained by continuous infusion of artificial saliva $\left(\mathrm{pH}=8.4 ; 9.8 \mathrm{~g}\right.$ of $\mathrm{NaHCO}_{3}$, $3.72 \mathrm{~g}$ of $\mathrm{Na}_{2} \mathrm{HPO}_{4}, 0.47 \mathrm{~g}$ of $\mathrm{NaCl}, 0.57 \mathrm{~g}$ of $\mathrm{KCl}, 0.053$ $\mathrm{g}$ of $\mathrm{CaCl}_{2} \cdot 2 \mathrm{H}_{2} \mathrm{O}$, and $0.128 \mathrm{~g}$ of $\mathrm{MgCl}_{2} \cdot 6 \mathrm{H}_{2} \mathrm{O}$ per L) at 2 different rates of 545 and $780 \mathrm{~mL} / \mathrm{d}$, approximating DL of 3.78 (LDL) and 5.42\%/h (HDL), respectively. These DL and solids RT were chosen to resemble values previously observed in vivo in sheep (Ranilla et al., 1998; Carro et al., 2000; Valdés et al., 2000). The HDL fermenters received diluted saliva $(70 \%)$ to infuse daily the same amount of salts in all fermenters and maintain similar $\mathrm{pH}$. Changes in the saliva composition were based on previous results (Carro et al., 1995, 2009). On d 11, a dose of $3.5 \mathrm{mg}$ of ${ }^{15} \mathrm{~N}$ (98\% enriched ${ }^{15} \mathrm{NH}_{4} \mathrm{Cl}$; Tracer SA, Madrid, Spain) was added into each fermenter to label the ammonia- $\mathrm{N}$ pool instantaneously. From $\mathrm{d} 11$ to 15 , a solution of ${ }^{15} \mathrm{NH}_{4} \mathrm{Cl}$ was added to the artificial saliva at a rate of $4.0 \mathrm{mg}$ of ${ }^{15} \mathrm{~N} / \mathrm{g}$ of dietary N. Each fermenter was flushed daily with $2 \mathrm{~L}$ of $\mathrm{CO}_{2}$ both before and after feeding, to remove gases produced during the fermentation and the air introduced in the fermenter during feeding, respectively.

On d 11, 12, 13, and 14, $\mathrm{pH}$ of the fluid from each fermenter was determined immediately before feeding, and the following samples were collected. The 
gas produced was collected daily in hermetic bags to determine the gas production and the concentrations of $\mathrm{CH}_{4}$. Liquid effluent was collected daily in flasks containing a solution of $\mathrm{H}_{2} \mathrm{SO}_{4}(20 \%$; vol/vol) to maintain $\mathrm{pH}$ below 2 . One milliliter of effluent was added to 1 $\mathrm{mL}$ of deproteinizing solution (10\% of metaphosphoric acid and $0.06 \%$ crotonic acid; wt/vol) for VFA determination, and $5 \mathrm{~mL}$ of effluent were stored at $-20^{\circ} \mathrm{C}$ for ammonia- $\mathrm{N}$ and total lactate determinations. Two nylon bags ( 1 with forage and 1 with concentrate) from each fermenter were collected daily, washed twice with $40 \mathrm{~mL}$ of fermenter liquid, and then washed in the cold rinse cycle $(20 \mathrm{~min})$ of a washing machine. The DM apparent disappearance was calculated from the loss in weight after oven-drying at $60^{\circ} \mathrm{C}$ for $48 \mathrm{~h}$, and the residues were analyzed for NDF and ADF to estimate $\mathrm{NDF}$ and ADF disappearance. On d 12, approximately $4 \mathrm{~mL}$ of fermenter fluid were taken at 3,6 , and $9 \mathrm{~h}$ after feeding, and $\mathrm{pH}$ was measured immediately. In addition, $4 \mathrm{~mL}$ of fluid was taken before feeding on $\mathrm{d}$ 14 , and immediately frozen at $-80^{\circ} \mathrm{C}$ for determination of carboxymethylcellulase, xylanase, and amylase activities.

On d 15 and 16, a water solution saturated with $\mathrm{HgCl}_{2}(5 \mathrm{~mL})$ was added (replacing the $\mathrm{H}_{2} \mathrm{SO}_{4}$ solution, which could cause bacterial lysis) to the overflow containers, which were held in an ice-water bath to impede microbial growth. Approximately $500 \mathrm{~mL}$ of effluent was used for isolation of liquid-associated microbial pellets (LAM) by differential centrifugation (Ranilla and Carro, 2003). The contents of nylon bags removed on d 15 and 16 were used to determine the growth of solidassociated microorganisms (SAM). Approximately $20 \%$ of solids content from each nylon bag was frozen and lyophilized for determination of DM, NAN, and ${ }^{15} \mathrm{~N}$ enrichment. The SAM pellets were isolated after treating the remaining solids content with a saline solution $(0.85 \% \mathrm{NaCl})$ of $0.1 \%$ methylcellulose at $38^{\circ} \mathrm{C}$ for 15 min with continuous shaking. The residue was then filtered through 2 layers of nylon cloth $(40-\mu \mathrm{m}$ pore size), resuspended in cold $\left(4^{\circ} \mathrm{C}\right)$ saline solution of $0.1 \%$ methylcellulose, and chilled at $4^{\circ} \mathrm{C}$ for $24 \mathrm{~h}$. The filtrate obtained each day was mixed and used to isolate SAM by differential centrifugation as described by Ranilla and Carro (2003). Substrate was also analyzed for its natural ${ }^{15} \mathrm{~N}$ content, and this value was used for background correction before ${ }^{15} \mathrm{~N}$ infusion.

\section{Analytical Procedures}

Dry matter (method 934.01), ash (method 942.05), and N (method 984.13) were determined according to the AOAC (1999). Neutral detergent fiber and ADF analyses were carried out according to Van Soest et al.
(1991), using an Ankom ${ }^{220}$ Fiber Analyzer unit (Ankom Technology Corporation, Fairport, NY). Sodium sulfite and heat-stable amylase were used in analysis of NDF and ADF, and they were expressed inclusive of residual ash. The volume of gas produced was measured with a drum-type gas meter (model TG1; Ritter Apparatebau GmbH, Bochum, Germany) and the concentration of methane was analyzed by GLC as described by Carro and Miller (1999). Preparation of samples for ${ }^{15} \mathrm{~N}$ analysis followed the procedures described by Carro and Miller (1999), and analyses of ${ }^{15} \mathrm{~N}$ enrichment were performed by GC-MS (VG Prism II; Prism, Middlewich, UK) connected in series to a Dumas-style $\mathrm{N}$ analyzer (Model 1108; Carlo Erba Instruments, Milan, Italy).

For determination of enzymatic activities in ruminal fluid samples, samples were defrosted, and cells were lysed using a Mini-Beadbeater (BioSpec Products Inc., Bartlesville, OK) to release intracellular enzymes. The treatment consisted of three 60 -s pulses at $4^{\circ} \mathrm{C}$ using 0.1-mm glass beads. Unbroken cell material was removed by centrifugation $\left(10,000 \times g, 10 \mathrm{~min}, 4^{\circ} \mathrm{C}\right)$, and the supernatant $(200 \mu \mathrm{L})$ was used for analyses. Carboxymethylcellulase, xylanase, and amylase activities were determined following the procedures of Colombatto and Beauchemin (2003) with the modifications described by Giraldo et al. (2008), using as substrates carboxymethylcellulose, oat spelt xylan, and soluble starch, respectively. Enzymatic activities were expressed as nanomoles of glucose or xylose released from the corresponding substrates by $1 \mathrm{~mL}$ of ruminal fluid in $1 \mathrm{~min}$ at $39^{\circ} \mathrm{C}$ and $\mathrm{pH} 6.5$.

\section{Calculations and Statistical Analyses}

The amount of OM apparently fermented was estimated from VFA production by using the equation proposed by Blanchart et al. (1989). The proportion of digesta NAN (liquid or solid) of microbial origin was estimated for each fermenter by dividing the ${ }^{15} \mathrm{~N}$ enrichment (atom percent in excess) of the NAN portion of digesta by the enrichment of the corresponding microbial pellets (LAM or SAM). Daily microbial $\mathrm{N}$ production $(\mathrm{mg} / \mathrm{d}$; LAM or SAM) was estimated by multiplying total NAN production in the corresponding digesta (liquid or solid) by the proportion attributed to the microbes. Total daily microbial production was calculated as the sum of the flows of LAM and SAM. The EMG was expressed as milligrams of microbial $\mathrm{N}$ per gram of OM apparently fermented.

The volume of gas produced in fermenters $(\mathrm{L} / \mathrm{d})$ was corrected for temperature $\left(0^{\circ} \mathrm{C}\right)$ and pressure $(1.013 \times$ $\left.10^{5} \mathrm{~Pa}\right)$ conditions, and the amount of methane produced (mmol) was calculated by multiplying the gas produced by the methane concentration in the analyzed 
sample. Fermentation data were analyzed as a $2 \times 2$ factorial arrangement of treatments and 4 replicates using the MIXED procedure (SAS Institute Inc., Cary, NC). The effects of treatments and their interaction were considered fixed, and the effect of sampling day was evaluated as a repeated measure. In the analysis of results of microbial growth and enzyme activities in the fermenters, day of sampling was excluded from the model. When a significant effect of treatment $(P$ $\leq 0.05)$ was detected, differences among means were tested using Tukey's multiple comparison test.

\section{RESULTS AND DISCUSSION}

The experimental approach used in the present study differed from others carried out previously to analyze the effects of DL and solids RT on microbial growth and ruminal fermentation. Because one main objective was to investigate the effect of DL and RT, we tried to isolate these factors and to maintain similar $\mathrm{pH}$ in all fermenters. In addition, solids RT is not affected by DL in Rusitec fermenters, and effects of both factors can be analyzed independently. To our knowledge, this is the first study in which a different RT was selected for forage and concentrate in Rusitec fermenters, because usually the diet is incubated for $48 \mathrm{~h}$. This would more closely reflect the in vivo situation, because concentrate feeds have been shown to have shorter RT in the rumen compared with forages (Mambrini and Peyraud, 1997).

As expected, an increase $(P<0.001)$ in the amount of effluent was observed when DL was augmented (Table 2), whereas $\mathrm{pH}$ before feeding and mean $\mathrm{pH}$ over $9 \mathrm{~h}$ after feeding were not affected $(P=0.47$ and 0.67 , respectively) by DL. There was no concentrate $\mathrm{RT} \times \mathrm{DL}$ interaction for these variables $(P=0.67$ and 0.95, respectively). Apparent disappearance of diet DM, NDF, and ADF was greater $(P<0.001)$ in HDL compared with LDL fermenters, which agrees with some previous studies (Crawford et al., 1980; Eun et al., 2004; Fondevila and Pérez-Espés, 2008) but it is in contrast with others in which no effect of DL was observed (Czerkawski and Breckenridge, 1977; Carro et al., 1995). Meng et al. (1999) observed that increasing DL resulted in a decrease in DM digestibility for 3 different diets, which was attributed to a concomitant decrease in solids RT, because the single-effluent, continuous-culture system used in their study allowed solid and liquid fractions to flow simultaneously out of the fermenters. Probable reasons for the discrepancies among studies include differences in the diets incubated, types of fermenters, and inocula characteristics. The basal diet in our study was chosen to be representative of those used in sheep in field conditions in Spain, but its composition was different from dairy cow diets used in other studies. In Rusitec fermenters, solids RT is not affected by DL, because the diet is incubated in nylon bags, which are taken out at a fixed time. Moreover, it has to be taken into account that most of the previous studies have been conducted using ruminal inoculum from cattle, whereas inoculum from sheep was used in the present study. In our study, there were concentrate RT $\times$ DL interactions for apparent disappearance of concentrate DM, NDF, and ADF $(P=0.01,0.003$, and 0.03 , respectively), indicating that the effects of $\mathrm{DL}$ on diet disappearance were more pronounced in T48 compared with T24 fermenters (Table 2).

Contrary to our expectations, apparent disappearance of forage DM, NDF, and ADF was affected by concentrate RT, being greater in T24 compared with T48 fermenters $(P=0.001,<0.001$, and 0.001 , respectively). Because forage RT was T48 in all fermenters, the observed effect cannot be attributed to this factor. As expected, apparent disappearance of concentrate increased $(P<0.001)$ as concentrate RT increased from T24 to T48, which is in accordance with previous studies (Crawford et al., 1980; Shriver et al., 1986; Schadt et al., 1999).

Only a few studies have investigated the effects of DL and solids RT on methane production by ruminal microorganisms. In the present study, methane production was not affected $(P=0.69)$ by DL (Table 3$)$. In contrast, Eun et al. (2004) observed an increase $(P=$ 0.01) in methane production as DL was augmented, and Isaacson et al. (1975) reported a decrease in methane formation when DL increased. Methane production is strongly affected by ruminal pH, and Russell (1998) showed that methane production in vitro decreased dramatically at $\mathrm{pH}$ below 6.3. In our study, however, $\mathrm{pH}$ was not affected by DL, and this factor can be ruled out (Table 2). In contrast, in the study of Eun et al. (2004), pH increased from 5.0 to 6.3 as DL increased from 3.2 to $12.5 \% / \mathrm{h}$, and the greater $\mathrm{pH}$ could have contributed to the increased methane production observed at the highest DL. The growth rate of methanogens is relatively slow, which could result in reduced methanogenic archea numbers at high DL (Eun et al., $2004)$, but the highest DL in our study $(5.4 \% / \mathrm{h})$ did not have a negative impact on methane production. Methane production was greater $(P=0.006)$ in T48 compared with T24 fermenters, which is in accordance with the greater $(P<0.001)$ acetate and lower $(P<$ $0.001)$ propionate proportions observed in T48 fermenters (Table 3). Similar effects of solids RT have been reported previously (Crawford et al., 1980; Schadt et al., 1999) and would reflect the reduced proportions of fiber digested as solids RT decreased.

Changes in DL have been reported to affect VFA production and the VFA profile, but the effect has been 
Table 2. Effect of retention time (RT, 24 or $48 \mathrm{~h}$ ) and dilution rate (DL, high or low) on the amount of effluent, pH, and apparent disappearance of diet in Rusitec fermenters ${ }^{1}$

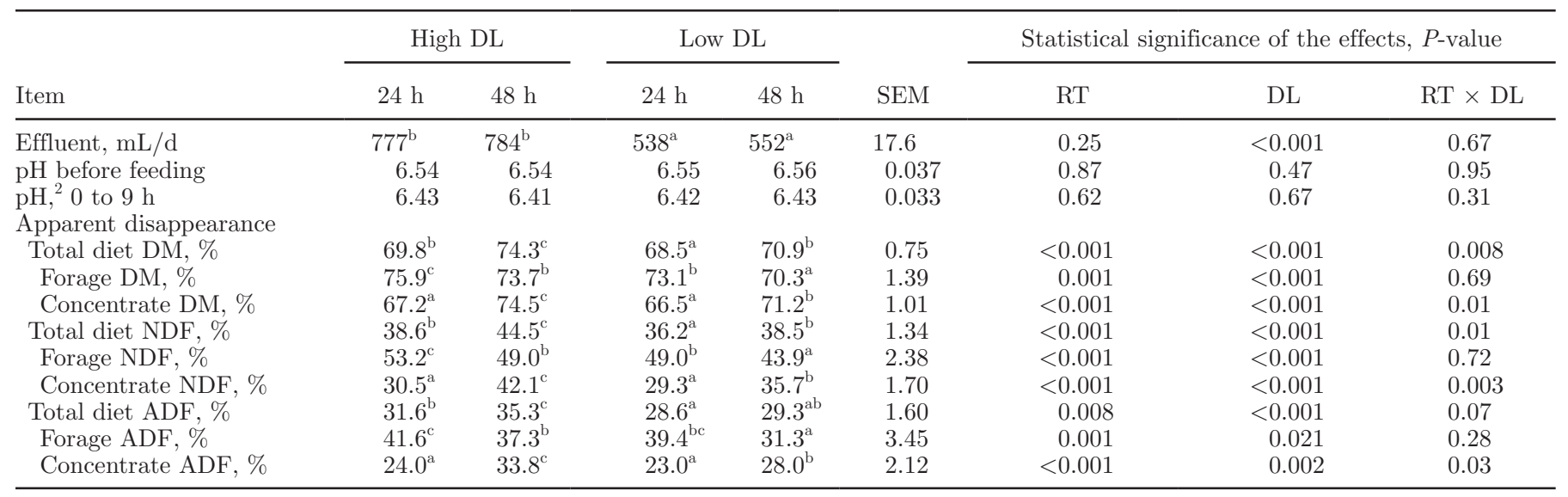

${ }^{\mathrm{a}-\mathrm{c}}$ Within a row, means without a common superscript letter differ, $P \leq 0.05$ (Tukey's test).

${ }^{1}$ Values are the mean of 4 daily observations in each of 4 fermenters $(\mathrm{n}=16)$. Diet was composed of $30 \%$ alfalfa hay and $70 \%$ concentrate (DM basis).

${ }^{2}$ Values were determined at $0,3,6$, and $9 \mathrm{~h}$ after feeding.

variable. In agreement with others (Stern and Hoover, 1979; Crawford et al., 1980), HDL increased $(P<0.001)$ total VFA production compared with LDL. These results contrast with those from other studies, in which increasing DL has been found to decrease (Carro et al., 1995; Meng et al., 1999) or not to affect VFA production (Isaacson et al., 1975; Hoover et al., 1984; Eun et al., 2004). Increasing DL increased $(P<0.001)$ molar proportions of propionate without affecting acetate proportions, as has been documented in other studies (Isaacson et al., 1975; Carro et al., 1995). In contrast, molar proportions of propionate have been reported to be lower (Crawford et al., 1980) or not affected (Eun et al., 2004; Fondevila and Pérez-Espés, 2008) because of increased DL. No changes $(P=0.28)$ in butyrate proportions were observed in the present study, but others (Carro et al., 1995; Meng et al., 1999; Eun et al., 2004) have found a decrease in butyrate proportions as DL increased. These controversial results could be due to several factors, among them the type of diet (Meng et al., 1999).

In agreement with our results, Eun et al. (2004) observed greater proportions of isovalerate and valerate as DL increased, which might indicate enhanced prote-

Table 3. Effect of retention time (RT, 24 or $48 \mathrm{~h}$ ) and dilution rate (DL, high or low) on daily production of methane and VFA in Rusitec fermenters ${ }^{1}$

\begin{tabular}{|c|c|c|c|c|c|c|c|c|}
\hline Item & \multicolumn{2}{|c|}{ High DL } & \multicolumn{2}{|c|}{ Low DL } & SEM & \multicolumn{3}{|c|}{ Statistical significance of the effects, $P$-value } \\
\hline Methane, $\mathrm{mmol} / \mathrm{d}$ & $19.2^{\mathrm{a}}$ & $22.5^{\mathrm{b}}$ & $19.6^{\mathrm{a}}$ & $21.6^{\mathrm{b}}$ & 0.18 & $<0.001$ & 0.69 & 0.32 \\
\hline Acetate & $44.1^{\mathrm{a}}$ & $45.4^{\mathrm{b}}$ & $44.2^{\mathrm{a}}$ & $45.7^{\mathrm{b}}$ & 0.71 & $<0.001$ & 0.62 & 0.73 \\
\hline Propionate & $19.8^{\mathrm{d}}$ & $16.0^{\mathrm{b}}$ & 17.7 & $12.9^{\mathrm{a}}$ & 0.55 & $<0.001$ & $<0.001$ & 0.049 \\
\hline Valerate & $5.63^{\mathrm{d}}$ & $4.73^{\mathrm{c}}$ & $4.13^{\mathrm{b}}$ & $3.74^{\mathrm{a}}$ & 0.141 & $<0.001$ & $<0.001$ & 0.004 \\
\hline Isovalerate & $3.65^{\mathrm{b}}$ & $3.43^{\mathrm{c}}$ & $2.98^{\mathrm{b}}$ & $2.68^{\mathrm{a}}$ & 0.173 & 0.007 & $<0.001$ & 0.69 \\
\hline Caproate & $4.23^{\mathrm{a}}$ & $9.84^{\mathrm{b}}$ & $9.22^{\mathrm{b}}$ & $12.7^{\mathrm{c}}$ & 0.510 & $<0.001$ & $<0.001$ & $<0.001$ \\
\hline Acetate:propionate & $2.24^{\mathrm{a}}$ & $2.85^{\mathrm{c}}$ & $2.53^{\mathrm{b}}$ & $3.55^{\mathrm{d}}$ & 0.107 & $<0.001$ & $<0.001$ & $<0.001$ \\
\hline OM apparently fermented, ${ }^{2} \mathrm{~g} / \mathrm{d}$ & 8.05 & $7.86^{\mathrm{b}}$ & $6.87^{\mathrm{a}}$ & $6.99^{\mathrm{a}}$ & 0.265 & 0.78 & $<0.001$ & 0.26 \\
\hline Methane:VFA, $\mathrm{mol} / \mathrm{mol}$ & $0.205^{\mathrm{a}}$ & $0.230^{\mathrm{b}}$ & $0.229^{\mathrm{b}}$ & $0.237^{\mathrm{b}}$ & 0.0101 & 0.009 & 0.03 & 0.31 \\
\hline H recovery, \% & 88.8 & 91.6 & 91.8 & 89.2 & 2.62 & 0.93 & 0.83 & 0.047 \\
\hline
\end{tabular}

${ }^{\mathrm{a}-\mathrm{d}}$ Within a row, means without a common superscript letter differ, $P \leq 0.05$ (Tukey's test).

${ }^{1}$ Values are the mean of 4 daily observations in each of 4 fermenters $(\mathrm{n}=16)$. Diet was composed of $30 \%$ alfalfa hay and $70 \%$ concentrate (DM basis).

${ }^{2} \mathrm{OM}$ apparently fermented was estimated from the net production of acetate, propionate, butyrate, isobutyrate, isovalerate, and valerate (Blanchart et al., 1989). 
Table 4. Effect of retention time (RT, 24 or $48 \mathrm{~h}$ ) and dilution rate (DL, high or low) on daily production of ammonia-N and NAN, daily N flow of liquid-associated (LAM) and solid-associated microorganisms (SAM), and efficiency of microbial growth (EMG) in Rusitec fermenters ${ }^{1}$

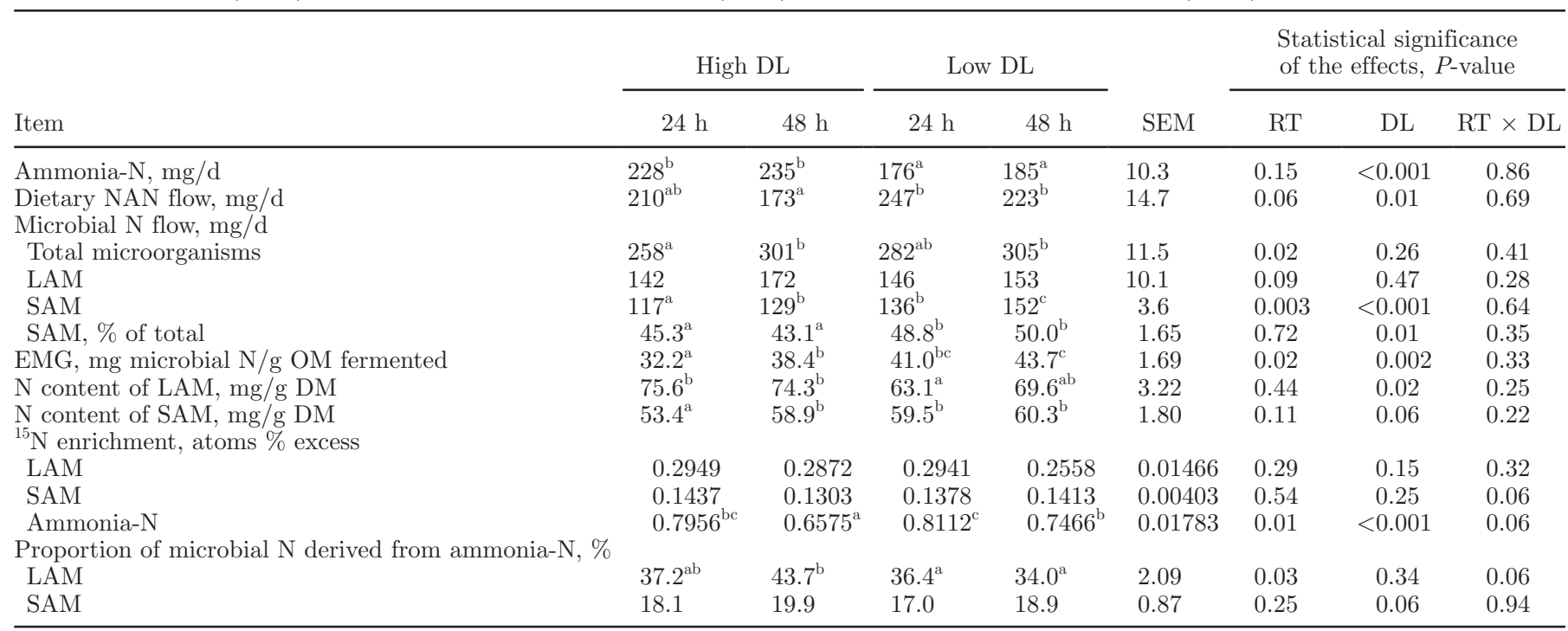

${ }^{\mathrm{a}-\mathrm{C}}$ Within a row, means without a common superscript letter differ, $P \leq 0.05$ (Tukey's test).

${ }^{1}$ Values are the mean of 1 daily observation in each of 4 fermenters $(n=4)$. Diet was composed of $30 \%$ alfalfa hay and $70 \%$ concentrate $(\mathrm{DM}$ basis).

olytic activity. This is further suggested by the greater $(P<0.001)$ ammonia-N production and the lower $(P$ $<0.001$ ) ammonia $-{ }^{15} \mathrm{~N}$ enrichment observed in HDL compared with LDL fermenters (Table 4). The greater ammonia-N production in HDL fermenters could have been due to either an enhanced rate of production or reduced utilization by ruminal microbes. The lower ammonia- ${ }^{15} \mathrm{~N}$ enrichment observed in HDL fermenters would indicate a greater ammonia- $\mathrm{N}$ production, because a similar amount of ${ }^{15} \mathrm{~N}$ was infused in each fermenter.

The production of VFA was greater $(P=0.006)$ in T48 compared with T24 fermenters, which is consistent with the greater apparent disappearance of diet observed in T48 fermenters. Increasing concentrate RT resulted in increased $(P<0.001)$ acetate and decreased propionate $(P<0.001)$, isovalerate $(P<$ $0.001)$, and valerate $(P=0.007)$ proportions. Readily fermented carbohydrates were probably fermented in the first hours of incubation, and only structural carbohydrates were available to ruminal microbes after $24 \mathrm{~h}$ of incubation, which would explain the increased acetate and decreased propionate proportions in T48 compared with T24 fermenters. The molar proportions of caproate and acetate:propionate ratio were lower $(P<0.001)$ in T24 compared with T48 fermenters, and in HDL compared with LDL fermenters. These results seem to indicate that the unphysiologically high caproate concentrations and acetate:propionate ratios found in previous experiments with Rusitec fermenters with high-concentrate diets (Gómez et al., 2005; Carro et al., 2009) might have been due to the high RT of concentrate feeds ( $48 \mathrm{~h}$ in all the cited experiments) and to the low DL (about 3.8\%/h). Using higher DL and shorter RT of concentrate in Rusitec fermenters could probably contribute to improving the simulation of in vivo fermentation when high-concentrate diets are used, as has been suggested previously (Carro et al., 2009). Hydrogen recoveries were in the range of those observed in previous experiments with Rusitec fermenters (Gómez et al., 2005; Giraldo et al., 2007), and were not affected by either concentrate RT $(P=0.93)$ or DL $(P=0.83)$.

Alterations in the microbial communities may have been indicated by changes in the $\mathrm{N}$ content of microbes (Table 4). Increasing DL increased $(P=0.02) \mathrm{N}$ content of LAM, but tended to decrease $(P=0.06) \mathrm{N}$ content of SAM. In contrast, there were no effects $(P>0.05)$ of concentrate RT on microbial $\mathrm{N}$ content, and no RT $\times$ DL interaction was detected $(P>0.05)$. The proportions of microbial $\mathrm{N}$ derived from ammonia- $\mathrm{N}$ were in the range of values found in other experiments conducted with Rusitec fermenters in our laboratory (unpublished results). The uptake of ammonia-N by SAM tended to be greater $(P=0.06)$ in HDL compared with LDL fermenters, which might indicate that microbial communities developed in the fermenters were affected by DL. This is further suggested by the fact that dietary NAN flow was greater $(P=0.01)$ in LDL compared with HDL fermenters, which indicates population shifts 
Table 5. Effect of retention time (RT, 24 or $48 \mathrm{~h}$ ) and dilution rate (DL, high or low) on carboxymethylcellulase, xylanase, and amylase activities in ruminal fluid in Rusitec fermenters ${ }^{1}$

\begin{tabular}{|c|c|c|c|c|c|c|c|c|}
\hline \multirow[b]{2}{*}{ Item } & \multicolumn{2}{|c|}{ High DL } & \multicolumn{2}{|c|}{ Low DL } & \multirow[b]{2}{*}{ SEM } & \multicolumn{3}{|c|}{$\begin{array}{l}\text { Statistical significance } \\
\text { of the effects, } P \text {-value }\end{array}$} \\
\hline & $24 \mathrm{~h}$ & $48 \mathrm{~h}$ & $24 \mathrm{~h}$ & $48 \mathrm{~h}$ & & $\mathrm{RT}$ & $\mathrm{DL}$ & $\mathrm{RT} \times \mathrm{DL}$ \\
\hline Carboxymethylcellulase & 99.3 & 97.9 & 92.1 & 94.9 & 2.45 & 0.75 & 0.06 & 0.41 \\
\hline Xylanase & $1,010^{\mathrm{a}}$ & $1,139^{\mathrm{b}}$ & $990^{\mathrm{a}}$ & $991^{\mathrm{a}}$ & 36.5 & 0.10 & 0.04 & 0.11 \\
\hline Amylase & 385 & 365 & 391 & 399 & 16.7 & 0.73 & 0.27 & 0.43 \\
\hline
\end{tabular}

to microbes with less proteolytic activity and agrees with the lower ammonia-N production. Schadt et al. (1999) observed that increasing solids RT in continuous cultures of ruminal microorganisms increased digestion of fiber and DM, but protein digestion was not greatly affected. This is in agreement with our results, because ammonia-N production was not affected $(P=0.15)$ by concentrate RT, and flow of dietary $\mathrm{N}$ tended $(P=$ $0.06)$ to be greater only in T24 compared with T48 fermenters.

Xylanase activity of ruminal fluid was greater $(P=$ 0.04 ) and carboxymethylcellulase activity tended to be greater $(P=0.06)$ in HDL compared with LDL fermenters, but there were no differences $(P=0.27)$ in amylase activity (Table 5). Because the daily flow of LAM was not affected by DL $(P=0.47$; mean values of 157 and $150 \mathrm{mg} / \mathrm{d}$ for HDL and LDL, respectively), differences in LAM concentrations between HDL and LDL were not expected, and the results would indicate that HDL promoted the development of microbial populations with greater fibrolytic activity, especially in T48 fermenters. This was further supported by the greater substrate NDF and ADF disappearance observed in HDL-T48 fermenters (Table 2). In contrast, enzymatic activities of ruminal fluid were not affected $(P=0.10$ to 0.75 ) by concentrate RT, and no interaction $\mathrm{RT} \times$ DL was detected ( $P=0.11$ to 0.43$)$ for any of these variables.

In general, in vitro studies with pure or mixed cultures of rumen bacteria have indicated a greater microbial growth and EMG with increasing DL (Isaacson et al., 1975; Stern and Hoover, 1979; Meng et al., 1999) and decreasing solids RT (Schadt et al., 1999), or both (Crawford et al., 1980; Shriver et al., 1986). In our study, DL did not affect total microbial $\mathrm{N}$ flow $(P=0.26)$. In contrast, Eun et al. (2004) reported that microbial growth was increased $(P=0.01)$ by increasing DL from 3.2 to $12.5 \% / \mathrm{h}$ in fermenters fed a high-concentrate diet, and Meng et al. (1999) observed that increasing DL from 2.5 to $20.0 \% / \mathrm{h}$ linearly increased $(P=0.01)$ the microbial $\mathrm{N}$ flow in fermenters fed 3 different diets. Because in these studies the $\mathrm{pH}$ increased with increasing DL, but was not affected by DL in our work, the results are not directly comparable. In addition, the DL in the present study were lower than those used in other studies with continuous-flow fermenters.

In Rusitec fermenters, the solid phase is removed when the nylon bags containing the substrate are taken out daily. The proportion of microbial $\mathrm{N}$ in the substrate taken out of the fermenters was greater $(P=$ 0.04 ) in HDL compared with LDL fermenters (47.5 and $42.9 \%$, respectively; results not shown), which would indicate that HDL promoted a greater colonization of feed particles. Although the proportion of microbial N in substrate residues was greater for HDL fermenters, the daily flow of SAM-N was lower $(P<0.001)$ compared with that in LDL fermenters (Table 4). This was due to the lower amount of substrate residues (forage and concentrate) recovered every day from HDL fermenters because of increased substrate degradation (Table 2). The SAM represented a lower $(P=0.01)$ proportion of total microbial $\mathrm{N}$ flow for HDL compared with LDL fermenters (mean values for both concentrate RT of 44.2 and $49.4 \%$, respectively), but the observed values were in the range of those found in fermenters (Ranilla and Carro, 2003) and in cattle (Vlaeminck et al., 2006) fed high-concentrate diets.

Although higher DL are usually associated with shorter RT in the rumen (Stern et al., 2006), in Rusitec fermenters, solids RT is not affected by DL. In our study, total microbial $\mathrm{N}$ flow was 1.12 times greater $(P$ $=0.02)$ in T48 compared with T24 fermenters. This was due to the greater $(P=0.003)$ SAM flow observed in T48 fermenters, because differences in LAM flow did not reach the significance level $(P=0.09)$. The proportion of microbial $\mathrm{N}$ in the substrate after incuba- 
tion into the fermenters was greater $(P=0.002)$ for T48 compared with T24 fermenters (49.5 and 40.9\%, respectively; results not shown), which could have been because microbes had a longer time for colonization of concentrate particles. Although the amounts of concentrate residues were lower in T48 fermenters because of the increased disappearance, the SAM flow was greater because of the increased amount of microbes attached to feed particles.

The values of EMG were in the range of those found in previous studies with fermenters fed high-concentrate diets (Meng et al., 1999; Carro et al., 2009). The EMG was decreased by increasing DL $(P=0.002)$ and decreasing concentrate RT $(P=0.02)$, but no $\mathrm{DL} \times \mathrm{RT}$ interaction $(P=0.33)$ was detected. In agreement with our results, Hoover et al. (1984) reported that at $\mathrm{pH}$ 6.5, EMG decreased as DL increased from 4 to $8 \% / \mathrm{h}$, although in their study EMG increased as DL increased from 8 to $16 \% /$ h. Our results, however, contrast with the lack of effect on EMG as solids RT increased from 28 to $40 \mathrm{~h}$ in fermenters maintained at nearly constant $\mathrm{pH}$ (6.56 and 6.44, respectively) reported by Hoover et al. (1982), and the decreased EMG observed by Schadt et al. (1999) as solids RT increased from 10 to $30 \mathrm{~h}$ and $\mathrm{pH}$ changed from 6.10 to 6.75 . It is possible that the different conditions in the 2 different types of fermenters [dual-flow, continuous-culture fermenters in the studies of Hoover et al. (1982) and Schadt et al. (1999)] contributed to the observed differences.

\section{CONCLUSIONS}

Increasing DL in Rusitec fermenters maintained at similar $\mathrm{pH}$ increased DM, fiber, and protein disappearance, VFA and ammonia-N production, and carboxymethylcellulase and xylanase activities of ruminal fluid, but did not affect methane production or microbial growth. Results suggest that increasing DL resulted in changes in microbial populations toward microbes with greater fibrolytic and proteolytic activities. Reducing concentrate RT from T48 to T24 decreased diet disappearance, production of VFA and methane, and microbial flow and its efficiency, but did not affect ammonia- $\mathrm{N}$ production or protein disappearance, which would suggest that proteolytic microbes were not affected by concentrate RT. There were significant RT $\times$ DL interactions for several measured variables, indicating that the effects of DL on ruminal fermentation in Rusitec fermenters can be influenced by concentrate RT. Finally, increasing DL and decreasing concentrate RT resulted in reduced molar proportions of caproate and acetate:propionate ratios, showing values in the range of those found in vivo. This would indicate that using higher DL and shorter concentrate RT than those typically used in Rusitec fermenters would contribute to improving the simulation of in vivo fermentation of high-concentrate diets.

\section{ACKNOWLEDGMENTS}

Funding was provided by the Spanish Comisión Interministerial de Ciencia y Tecnología (Project AGL2004-04755-C02-01). M. E. Martinez and S. Ramos gratefully acknowledge the receipt of scholarships from the Ministerio de Educación y Ciencia of Spain (AP2005-1797 and BES-2005-6842).

\section{REFERENCES}

AOAC. 1999. Official Methods of Analysis. 16th ed. 5th rev. AOAC Int., Gaithersburg, MD.

Blanchart, G., M. Durant, J. L. Barry, M. Bouiller-Oudot, and J. P. Jouany. 1989. Intérêts et limites des fermenteurs à flux semicontinu de type Rusitec dans l'étude des fermentations du rumen [Advantages and limits of the semi-continuous artificial rumen (Rusitec) for the study of rumen fermentation]. Ann. Zootech. 38:285-314.

Carro, M. D., P. Lebzien, and K. Rohr. 1995. Effects of pore size of nylon bags and dilution rate parameters in a semi-continuous artificial rumen. Small Rumin. Res. 15:113-119.

Carro, M. D., and E. L. Miller. 1999. Effect of supplementing a fibre basal diet with different nitrogen forms on ruminal fermentation and microbial growth in an in vitro semicontinuous culture system (Rusitec). Br. J. Nutr. 82:149-157.

Carro, M. D., M. J. Ranilla, A. I. Martin-Garcia, and E. MolinaAlcaide. 2009. Comparison of microbial fermentation of highand low-forage diets in Rusitec, single-flow continuous-culture fermenters and sheep rumen. Animal 3:527-534.

Carro, M. D., C. Valdés, M. J. Ranilla, and J. S. González. 2000. Effect of forage to concentrate ratio in the diet on ruminal fermentation and digesta flow kinetics in sheep. Anim. Sci. 70:127-134.

Colombatto, D., and K. A. Beauchemin. 2003. A proposed methodology to standardize the determination of enzymatic activities present in enzyme additives used in ruminant diets. Can. J. Anim. Sci. $83: 559-568$

Colucci, P. E., G. K. MacLeod, W. L. Growum, I. McYillan, and D. J. Barney. 1990. Digesta kinetics in sheep and cattle fed diets with different forage to concentrate ratios at high and low intakes. J. Dairy Sci. 73:2143-2156.

Crawford, R. J. Jr., W. H. Hoover, and P. H. Knowlton. 1980. Effects of solids and liquid flows on fermentation in continuous cultures. I. Dry matter and fiber digestion, VFA production and protozoa numbers. J. Anim. Sci. 51:975-985.

Czerkawski, J. W., and G. Breckenridge. 1977. Design and development of a long-term rumen simulation technique (Rusitec). Br. J. Nutr. 38:371-384.

Eun, J. S., V. Fellner, and M. L. Gumpertz. 2004. Methane production by mixed ruminal cultures incubated in dual-flow fermenters. J. Dairy Sci. 87:112-121.

Fondevila, M., and B. Pérez-Espés. 2008. A new in vitro system to study the effect of liquid phase turnover and $\mathrm{pH}$ on microbial fermentation of concentrate diets for ruminants. Anim. Feed Sci. Technol. 144:196-211.

Giraldo, L. A., M. J. Ranilla, M. J. Tejido, and M. D. Carro. 2007. Influence of exogenous fibrolytic enzyme and fumarate on methane production, microbial growth and fermentation in Rusitec fermenters. Br. J. Nutr. 98:753-761.

Giraldo, L. A., M. J. Ranilla, M. J. Tejido, and M. D. Carro. 2008. Influence of direct-fed fibrolytic enzymes on diet digestibility and ruminal activity in sheep fed a grass hay-based diet. J. Anim. Sci. 86:1617-1623. 
Gómez, J. A., M. L. Tejido, and M. D. Carro. 2005. Mixed rumen micro-organisms growth and rumen fermentation of two diets in Rusitec fermenters: Influence of disodium malate supplementation. Br. J. Nutr. 93:479-484.

Hoover, W. H., R. J. Crawford Jr., and M. D. Stern. 1982. Effects of solids and liquid flows on fermentation in continuous cultures. III. Solids retention time. J. Anim. Sci. 54:849-854.

Hoover, W. H., C. R. Kincaid, G. A. Varga, W. V. Thayne, and L. L. Junkins Jr. 1984. Effects of solids and liquid flows on fermentation in continuous cultures. IV. $\mathrm{pH}$ and dilution rate. J. Anim. Sci. 58:692-699.

Isaacson, H. R., F. C. Hinds, M. P. Bryant, and F. N. Owens. 1975. Efficiency of energy utilization by mixed rumen bacteria in continuous culture. J. Dairy Sci. 58:1645-1659.

Mambrini, M., and J. L. Peyraud. 1997. Retention time of feed particles and liquids in the stomachs and intestines of dairy cows. Direct measurement and calculations based on faecal collection. Reprod. Nutr. Dev. 37:427-442.

Meng, Q., M. S. Kerley, P. A. Ludden, and R. L. Belyea. 1999. Fermentation substrate and DR interact to affect microbial growth and efficiency. J. Anim. Sci. 77:206-214.

NRC. 1985. Nutrient Requirements of Sheep. 6th ed. Natl. Acad. Press, Washington, DC.

Ranilla, M. J., and M. D. Carro. 2003. Diet and procedures used to detach particulate-associated microbes from ruminal digesta influence chemical composition of microbes and estimation of microbial growth in Rusitec fermenters. J. Anim. Sci. 81:537544 .

Ranilla, M. J., S. López, F. J. Giráldez, C. Valdés, and M. D. Carro. 1998. Comparative digestibility and digesta flow kinetics in two breeds of sheep. Anim. Sci. 66:389-396.
Russell, J. B. 1998. The importance of $\mathrm{pH}$ in the regulation of ruminal acetate to propionate ratio and methane production in vitro. J. Dairy Sci. 81:3222-3230.

Schadt, I., W. H. Hoover, T. K. Miller Webster, W. V. Thayne, and G. Licitra. 1999. Degradation of two protein sources at three solids retention times in continuous culture. J. Anim. Sci. 77:485-491.

Shriver, B. J., W. H. Hoover, J. P. Sargent, R. J. Crawford Jr., and W. V. Thayne. 1986. Fermentation of a high concentrate diet as affected by ruminal pH and digesta flow. J. Dairy Sci. 69:413419.

Stern, M. D., A. Bach, and S. Calsamiglia. 2006. New concepts in protein nutrition of ruminants. Pages $45-66$ in Proc. 21st Annu. Southwest Nutr. Manage. Conf., Tempe, AZ. University of Arizona, Tucson.

Stern, M. D., and W. H. Hoover. 1979. Methods for determining and factors affecting rumen microbial protein synthesis: A review. J. Anim. Sci. 49:1590-1603.

Valdés, C., M. D. Carro, M. J. Ranilla, and J. S. González. 2000. Effect of forage to concentrate ratio in complete diets fed to sheep on voluntary feed intake and some digestive parameters. Anim. Sci. 70:119-126.

Van Soest, P. J., J. B. Robertson, and B. A. Lewis. 1991. Methods for dietary fiber, neutral detergent fiber, and nonstarch polysaccharides in relation to animal nutrition. J. Dairy Sci. 74:3583-3597.

Vlaeminck, B., V. Fievez, D. Demeyer, and R. J. Dewhurst. 2006. Effect of forage:concentrate ratio on fatty acid composition of rumen bacteria isolated from ruminal and duodenal digesta. J. Dairy Sci. 89:2668-2678. 